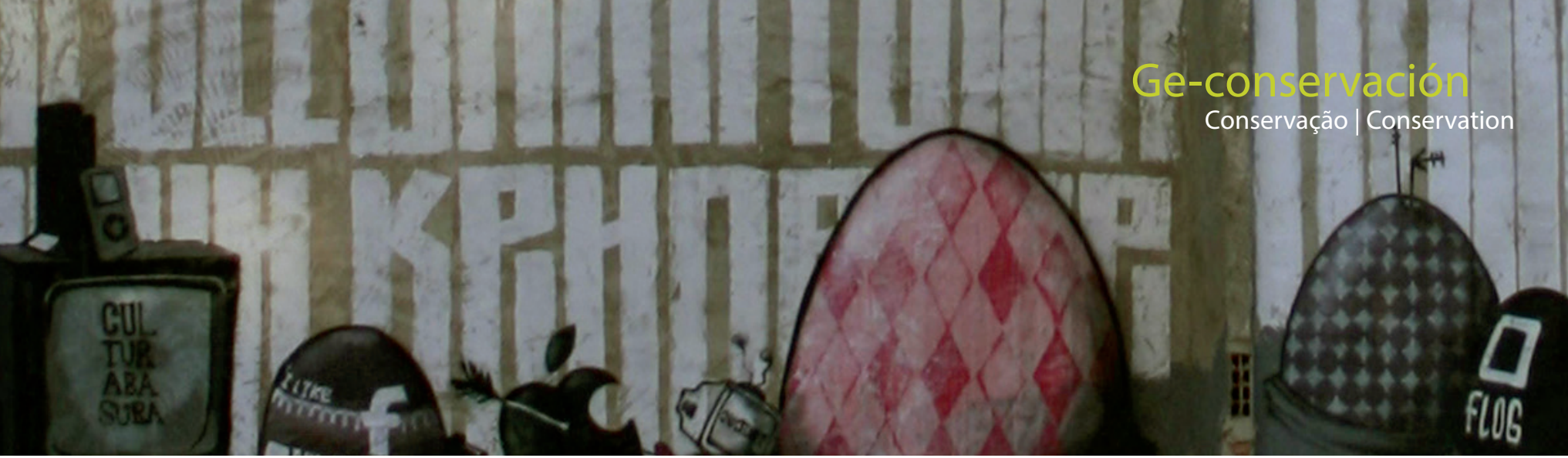

\title{
Propuesta de un modelo de registro para el análisis y documentación de obras de arte urbano
}

\author{
María Isabel Úbeda García
}

\begin{abstract}
Resumen: La presente investigación aporta a la comunidad de conservadores y restauradores, así como a otros especialistas que estudian el arte urbano desde diversos campos de trabajo y perspectiva, una ayuda específica y concreta para la identificación, estudio y análisis de las obras de arte urbano, así como un instrumento útil de clasificación. Se concreta en la propuesta de un modelo de ficha realizada con una metodología específica para documentar el arte urbano. La ficha consta de varios niveles de información: una parte formal y descriptiva (iconográfica, de documentación gráfica-audiovisual) y otra parte para el análisis crítico (iconológico) de la obra y contexto físico, histórico, artístico y social.
\end{abstract}

Palabras clave: documentación, arte urbano, conservación, metodología, análisis, ficha, catalogación, clasificación

\section{Proposal of a model of record for analysis and documentation of art works of street art}

Abstract: This research work aims to contribute to the community studying urban art from various fields of work and perspectives, a specific and concrete help to identify, study and analysis of the works of street art as well as a possible instrument of classification. This aims comes to reality in the proposal of a model record card with a specific methodology to document street art. The record card consists of several levels of depth: a formal and register record card (iconographic, graphic docs, audiovisual documentation) and a critical record card (iconological analysis) of the physical work and its historical, artistic and social context.

Key words: street art, conservation, documentation, methodology, analysis, record card, cataloging, classification

\section{Introducción y justificación}

Una de las cuestiones necesarias dentro del estudio teórico del Arte Urbano ${ }^{1}$ que puede servir para analizar su contexto, sus características y su importancia en el panorama creativo y artístico o comunicativo, es definir y delimitar qué obras se pueden encuadrar dentro de este campo, incluyendo las denominadas manifestaciones estéticas públicas independientes (MEPI)², que por estar en el espacio público son susceptibles de ser robadas o vendidas. Estas obras, necesitan una especial atención por parte de conservadores y restauradores y resto de equipo de profesionales ${ }^{3}$, para su estudio, al estar más expuestas y no tuteladas por ninguna entidad concreta. Aunque se estén dando casos de interés por parte de colectivos, asociaciones vecinales y profesionales de diferentes ámbitos de la cultura, las obras solo se suelen fotografiar con mirada de turista y la mayoría de las veces se pierden, sin llegar a ser documentadas como objetos artísticos.

El primer paso para obtener los registros documentales de las obras para una posterior catalogación, sería tener consciencia del lugar que ocupan dentro de la cultura oficial y qué consideración se les está dando en su entorno natural. 
El campo en el que se mueve el arte urbano bien podría denominarse como experimental, podría decirse que es el de una expresión artística conceptual, crítica y de comunicación directa con un público casual (los viandantes, vecinos y visitantes) y donde casi cualquier definición o clasificación escapa a la ortodoxia. No se pretende, aquí, sentar unas bases inamovibles para clasificar este tipo de intervenciones artísticas, sino aportar un sistema ordenado que permita sacar conclusiones sobre el tipo de obra que se analiza, para rescatar su esencia creativa. Pese a que se trata de una manifestación iniciada en el siglo XX, parece estar aún desubicada y siempre cuestionada, en una balanza que debe decidir entre pasar desapercibida y ser aceptarla como tendencia artística. Aun así, es una expresión viva y accesible que sigue mutando y desarrollándose. Además, en muchas ocasiones, no queda claro con exactitud a qué se refiere el propio término en sí, "arte urbano", ni si los artistas deben ser llamados artistas urbanos, a parte de la complejidad para comprender sus motivaciones y objetivos. El universo urbano comprende también las actuaciones de sus intermediarios, comisarios y promotores artísticos, sus propias acciones (estéticas o conceptuales) y todo aquello que pueda englobarse en un gran contenedor de creatividad popular que se encuentra comprometido en una carrera por ver si llegará a ser considerado como Arte, con mayúsculas, del siglo XXI.

\section{Objetivos y metodología}

\section{Objetivos}

Los cuatro objetivos principales de este estudio son los siguientes:

-1. Promover la clasificación y catalogación, estudio y documentación de las obras de arte urbano a partir de un número amplio de campos y parámetros que ayuden a conservadores y restauradores, así como historiadores del arte y otros agentes implicados, a estudiar estas obras.

- 2. Aportar una herramienta propia de catalogación y análisis pormenorizado para las obras de arte urbano, para definirlas y diferenciar las particularidades técnicas y conceptuales de su ejecución, además de unificar parámetros de documentación y registro; dirigido a cualquier profesional de este ámbito.

- 3. Contribuir, con base científica, a que el arte urbano sea reconocido como expresión artística por sí mismo, y por tanto, que las obras de arte catalogadas como obras de arte urbano sean admitidas dentro de un corpus como "Bien de Interés Común". Estas obras BIComún, como término popular acuñado por la asociación cultural Niquelarte en 2010, se refiere a los bienes aceptados por una comunidad que no se incluyen dentro de lo legislado en la ley de Patrimonio Histórico Artístico, ni a lo descrito para los Bienes de Interés Cultural (BIC). Estos objetos artísticos serían susceptibles de englobarse dentro del patrimonio cultural popular, lo que ayudaría a la declaración de algunas obras de arte urbano como BIComún, y por tanto, permitiría solicitar su protección administrativa para conservarlas (y en su caso restaurarlas) a través de una iniciativa popular y como parte de un legado a generaciones venideras, teniendo en cuenta que su esencia contracultural no resta sino que suma valores.

- 4. Contribuir a definir las distintas tipologías de arte urbano, como fórmula para el conocimiento de su esencia y del proceso creativo.

\section{Metodología}

Para llevar a cabo el estudio e investigación sobre arte urbano es necesario tomar medidas y acciones concretas, igual que para la conservación-restauración. Para que este tipo de manifestaciones artísticas consiga perdurar como legado cultural y que llegue a las siguientes generaciones, es necesario, además, que estos dos núcleos fundamentales, documentación y conservación, compartan un mismo objetivo.

Debido al carácter ilegal de muchas obras, si no se documentan adecuadamente, en poco tiempo se convierten en meros vestigios digitales -fotografías, vídeos, descripciones subjetivas- y reproducciones de merchandising, pero las piezas originales no sobreviven, ni tampoco la documentación objetiva y descriptiva de los materiales utilizados. Por no hablar de la motivación o el proceso creativo seguido por el artista. Aunque es imposible documentar toda la producción artística actual y en ocasiones el soporte será inevitablemente efímero -por su propia idiosincrasia, por casuística o por decisión de sus autores- es evidente que las obras realizadas en la calle representan un medio de expresión que hay que abordar.

De este modo, se propone una metodología desde la perspectiva del conocimiento de las herramientas de descripción usadas hasta ahora por la Historia del Arte, extrapolables y adaptadas para clasificar y desarrollar un análisis crítico de las obra de arte urbano. Este estudio y propuesta se basa en un registro queaporta documentación gráfica, audiovisual, descriptiva y formal. Una ficha, -en realidad un conjunto de fichas- con diferentes campos de interés para la obra y su conocimiento, donde poder aportar una parte crítica que contribuya al análisis de la misma, así como de su contexto físico, histórico, artístico y social. En una fase posterior del estudio, se realizará una entrevista al autor y la gente del entorno de la obra. Durante esa fase, será de especial utilidad un cuestionario para los artistas y el público; así como un registro de aquellas entidades públicas o privadas que se encarguen de organizar actividades donde intervenga el arte urbano.

El modelo de estas herramientas (fichas y entrevista) estará jerarquizado y relacionado según unos campos 
temáticos (metadatos), con un amplio número de subcampos y parámetros organizados de menos a más (detalles), seleccionados bajo unos criterios objetivos y adaptados a las características observadas en las obras de arte urbano.

\section{En busca de una definición}

Existen distintos puntos de partida desde los que analizar estas obras de arte urbano para su clasificación y estudio: por un lado, el estético, por otro lado, su mensaje o su implicación social y finalmente, el contexto o entorno, representado por el barrio o por un concepto espacial más amplio, en el que contemplar valoraciones de grupos organizados como fans de autores, investigadores y periodistas afines a determinados tipos de obras o artistas, que se encuentran entre la comunidad de consumo del arte urbano.

El"arte urbano"es un movimiento artístico y un término que "se utiliza para definir varias corrientes artísticas que son esencialmente diferentes entre sí" una expresión social y reivindicativa que solo puede darse en los espacios públicos comunes y cada vez va siendo más compleja, rica y extensa como para analizarlo desde un solo campo de investigación o perspectiva. Aunque el término postgrafiti se haya superado, es una definición que sitúa bien donde se encuentra el ojo del huracán de su estudio.

Por este motivo, para esta propuesta metodológica, se han investigado herramientas de clasificación y documentación que comprendan el mayor número posible de puntos de vista, para permitir las descripciones de los parámetros más interesantes que marquen su contexto y documentar las obras de arte urbano según su naturaleza, ya sean intervenciones, instalaciones sobre soporte mural o cualquier manifestación independiente, con marcos descriptivos que no opriman su esencia misma.

Esta propuesta metodológica parte, como estudio teórico, desde la Historia del Arte, y tomando al Arte Urbano ${ }^{5}$ como si se tratara de un movimiento artístico y social, como corriente artística o como un periodo ${ }^{6}$ dentro de la Historia del Arte, sin olvidar que el "arte urbano" puede tener unos valores ideológicos de activismo particulares.

\section{Modelo metodológico utilizado}

El presente estudio se encuentra cercano al modelo metodológico del análisis de obras de arte de la Escuela de Warburg, donde estudiosos como Gombrich, Panofsky o Wittkower, entre otros, señalan que la obra de arte es algo más que su forma, y a su vez, hay que analizarla para conocer su significado y simbolismo, de ahí que se realice un estudio analítico de su iconografía e iconología. Esta escuela propone que el Arte nos brinda conocimiento sobre el propio ser humano y su historia, vinculando diversas partes del conocimiento general al conocimiento particular de las obras de arte.

Siguiendo el tipo de análisis que Panofsky propone, con su niveles de lectura y compresión de obras en tres estadios: el formal o temático, el significado (iconografía) y la iconología (su significado en el contexto de la obra, del autor y del estudio), se abordará el estudio y análisis de las obras de arte urbano, sirviendo de referente para la selección de parámetros y su jerarquización.

Por ello, se propone iniciar el análisis de la obra de lo particular a lo general, para llegar finalmente a definir las peculiaridades de la misma.

El estudio propuesto se subdivide en varios campos y niveles, desde los datos sobre morfología (dimensiones del soporte, materiales, herramientas) y lo formal (color, composición, estructura), hasta el contenido estético, de significado artístico o social.

También se añaden otros campos de interés para la investigación, que generalmente no acompañan a una ficha al uso; campos que completan la visión y comprensión global de las necesidades y situación de la obra tales como: exposición o musealización (si se ha dado), interés del autor-es por la conservación-restauración de sus intervenciones, la situación de protección, el estado de conservación y datos técnicos que ayuden -en el caso de necesitarlo- a iniciar un plan de conservación preventiva, o los datos y detalles de restauración si finalmente se necesita o se ha realizado; y otros campos de utilidad, como la financiación (en el caso de una obra de encargo), y un listado de etiquetas digitales con las que se puede buscar y encontrar la obra.

Lo que se espera conseguir con esta amplia selección de campos y parámetros es, en realidad, un estudio lo más profundo y conciso posible, que aporte una valoración, lo más objetiva posible, de la obra y su contexto.

\section{Fases de estudio}

\section{Las fases de estudio se clasifican en cinco:}

- 1. Investigación sobre las metodologías de análisis y crítica del arte, realizando una comparativa de los tipos de catalogación e inventarios empleados en la clasificación de obras de arte contemporáneo, susceptibles de ser usados para el arte urbano.

Tipos de documentación existente y fichas técnicas utilizadas por los agentes de estudio de obras de arte urbano y otro tipo de obras de arte estudiadas para su conservación. Hasta la fecha se cuentan con diversos ejemplos de fichas y entrevistas de profesionales del ámbito histórico, la conservación y la restauración, así 
como de la catalogación de bienes artísticos de museos, instituciones sobre patrimonio o entidades privadas (profesionales autónomos dedicados a la restauración o empresas de subasta o tasación de obras de arte, por ejemplo).

Estudio y búsqueda de las nuevas posibilidades de documentación visual y audiovisual, gráfica y de nuevas tecnologías, como la geolocalización, para obtener un patrón que permita conocer la ubicación de las obras de arte urbano; la captura de imagen tradicional y de última generación tecnológica, como la imagen tomada por drones, captura de alta definición, etc.; información mediante etiquetado como el hashtag, y otros tag.

Estudio de los medios de difusión y divulgación sobre obras de arte y artistas, tanto los medios convencionales como los nuevos tipos de contenidos online -divulgativo científico o de ocio-, redes sociales principalmente, o revistas virtuales, vídeos documentales de los propios artistas o usuarios y seguidores de arte urbano en youtube, vimeo, etc.

\section{- 2. Selección y propuesta de parámetros divididos por} campos. Clasificación y organización de campos de interés según el análisis de la obra a varios niveles: técnico, formal, iconográfico, crítico y contextual (campo iconológico): histórico, artístico y social, económico y político.

- 3. Categorización de marcadores. Varias subfichas dentro de la ficha general, desde el registro de la ficha estándar hasta campos más específicos, que en ocasiones no hará falta concretar. Parámetros seleccionados por niveles y campos con descripciones.

- 4. Exposición y testado. A realizar con los modelos de las fichas para su test de stress o prueba de utilidad en el futuro. En fase de realización aún; para analizar y debatir en el Grupo de Arte Urbano y Conservación ${ }^{7}$

- 5. Conclusiones. Referentes tanto al modelo de registro final que se presenta (las fichas, o ficha global) como a observaciones generales del estudio sobre la realización del registro en sí.

\section{Arte urbano y las dificultades de acotación}

Ante la gran amplitud de manifestaciones artísticas englobadas en el arte urbano ${ }^{8}$, supone un reto describir qué es una obra de arte urbano. Actualmente hay una fuerte corriente muralista que nada tiene que ver con los orígenes del arte callejero, que asume su lenguaje pero está más cercano a lo meramente decorativo y pretende embellecer las calles o entornos ruinosos; por no hablar de las obras realizadas con fines utilitarios o mercantiles. En otras ocasiones, aunque mantienen su fuerza expresiva y combativa, hay obras que se desarrollan bajo fórmulas de festivales, convocatorias o jornadas, por lo que dejan de estar en un marco ilegal (algo que originariamente las caracterizaba). Por otro lado, el factor de localización y selección de espacios tampoco es determinante, pues, a día de hoy, no sólo se encuentran obras en rincones oscuros o de difícil y prohibido acceso, sino en calles principales, fachadas emblemáticas o interiores -como naves industriales o edificios abandonados o antiguas iglesias desacralizadas-. En cuanto al factor "lugar", la urbe (la ciudad, barrios y zonas deprimidas) también ha cambiado como elemento de conquista, puesto que encontramos pueblos pequeños o el mismo campo, que han sido tomados como contexto de los distintos lenguajes del arte urbano.

Por todo ello, se ha optado por buscar parámetros y campos lo más diversos posibles donde clasificar o catalogar las obras en sí, para saber si pueden ser denominadas como obras de arte urbano, y a qué tipo de expresión nos enfrentamos.

\section{La importancia de la terminología a la hora de docu- mentar}

El vocabulario o la terminología de uso, tanto en la práctica como en la teoría de esta forma de expresión artística, es también una de las "dificultades" añadidas al estudio del corpus de obras de arte urbano, pues está en pleno proceso de desarrollo y definición, aunque, cada vez hay más un consenso en determinados términos, en parte gracias a investigadores ${ }^{9}$ que estudian este tipo de manifestaciones artísticas, pero sobre todo gracias a la información que se va a añadiendo a través de las redes sociales y el reconocimiento social de los artistas, que ofrecen cada vez más entrevistas.

Encontramos que, según las corrientes estilísticas, el tipo de intervenciones o los lugares de procedencia de los autores, se utiliza un determinado tipo de vocabulario o terminología diferente, incluso, al referirse a las técnicas similares, por ejemplo. Los encargados de difundir el arte urbano también suelen utilizar diferentes términos $y$, en las redes sociales, prima la imagen por encima de la información del contenido. Por ello, a la hora de investigar y documentar se debe proceder con cautela, para poder describir correctamente las técnicas de ejecución.

Según la procedencia de los artistas (del grafiti, del postgrafiti o del arte convencional, con estudios artísticos académicos) se definen las obras de una manera u otra. Grafiteros y demás, tienen un registro de vocablos muy extenso a la hora de hablar sobre sus obras, sus procesos de factura y las técnicas empleadas, sin embargo entre los artistas más académicos que trabajan en las calles, el vocabulario suele ser otro. En cualquier caso, hay una gran riqueza de expresiones y términos que podemos y debemos recabar, registrar y utilizar en la realización de la ficha. 


\section{Documentar para conservar}

Al comienzo del estudio y en la fase de selección de parámetros, se plantean los tipos de clasificación posibles para un número determinado de elementos definidos, organizando los temas mediante un organigrama de tipo árbol. Se establece una amplia cantidad de campos, con unos parámetros objetivos evaluables, donde albergar información concreta, como la valoración artística y científica, evitando los datos subjetivos de opinión.

Es conveniente señalar que el estudio parte de los criterios de selección de campos y parámetros empleados en la catalogación y documentación convencional empleados en otros campos del conocimiento, como la Historia del Arte y de la Conservación, transformándolos según las necesidades del arte urbano.

Como ejemplos en uso, se han analizado diferentes tipos de fichas técnicas y descriptivas sobre arte convencional, y referimos aquí algunas de las que más nos han interesado, como la ficha técnica estándar de las obras del Museo del Prado, el de la Tate Britain en su modalidad online ${ }^{10}$, ambas con enlaces a otras referencias mediante hashtag. Estas fichas tienen una interesante estructura interna con enlaces a otras obras del autor, datos básicos de la obra seleccionada, y, lo más interesante, enlaces a parámetros temáticos, según la iconografía y temática de la obra (remitiendo a obras de otros autores por afinidad), también a modo de hashtag, para la consulta de público general. También se ha tomado la referencia del catálogo de enseres de Museo Cerralbo (versión online) e inventario de obras catalogadas, porque se ocupa de objetos, no solo de pintura, y comparte tipología de ficha con el resto de museos estatales ${ }^{11}$. Además, se considera oportuno mencionar que tras los campos básicos y habituales es posible crear enlaces a otros parámetros, como el "contexto cultural" o "estilo".

En cuanto a los ejemplos estudiados dentro del campo de la conservación-restauración, se han analizado varias propuestas ${ }^{12}$ donde se propone el estado de conservación de la obra como parte fundamental de la ficha técnica, tras los datos generales y estudio técnico y material. También se ha analizado el modelo de ficha básico que proponen Rosa Gasol y Rosa Senserrich al alumnado de la Facultad de Bellas Artes de Barcelona para el estudio y primer contacto con los murales: "Examen, diagnosi i documentació. Documentació i identificació de la pintura mural al carrer". En este caso, parece interesante manejar también un tipo de ficha más concreto, pues se limitan al "mural al carrer", primando la tipología de obra sobre otros campos, aunque, no obstante, el resto de datos técnicos al uso siguen apareciendo. Tras la parte de datos formales, aparecen los campos más técnicos y específicos para los restauradores y conservadores de este tipo de piezas: como "descripción de materiales y técnicas de aplicación" o "estado de conservación y degradación" con sus subcampos. También aporta bastante a nuestro estudio el modelo de ficha que se utiliza en algunos talleres de restauración, para documentar trabajos de restauración arqueológica, donde los gráficos y el "estado del terreno" o "factores de deterioro" (con los agentes de deterioro divididos en "agentes biológicos" y "factores geomorfológicos") son fundamentales.

Además, se han extraído elementos de las formas de catalogación de las bases de datos online, como Tesauro, cuyos parámetros son muy extensos, aunque contienen metadatos y campos muy concretos para la catalogación digital actual, o DOMUS, el sistema integrado de documentación y gestión museográfica desarrollado por el Ministerio de Cultura, una aplicación informática para el catálogo y gestión de los fondos museográficos y documentales de los museos españoles, nacido a partir del informe "Normalización Documental de Museos: elementos para una aplicación informática de gestión museográfica" (Ministerio de Cultura, 1996). Se han analizado, a su vez, las recomendaciones para documentar la imagen en los catálogos del Instituto Andaluz de Patrimonio Histórico porque aportan interés a nivel documental, en cuanto a la amplia tipología de formas de captura de imagen y sus posibilidades para el arte urbano. Y por último, se han extraído elementos interesantes del Inventario de Intervención y Conservación del Archivo IAPH con su Catálogo de obras restauradas ${ }^{13}$.

Cuando la ficha pertenece a una serie de obras, catálogo o colección concreta, lleva siempre un número de registro o un código, que en Arte Urbano puede sustituirse por los parámetros de geolocalización, sus coordenadas. Las obras de los museos se refieren a colecciones y tipologías del propio museo, pero en el caso del modelo de registro de obra de arte urbano que aquí se propone, aunque también está pensado para formar parte de inventarios u otros compendios más generales, se puede utilizar de forma particular en estudios individualizados.

Por otro lado, la documentación gráfica siempre está presente, y sigue siendo la fotografía el medio más útil. Cuando la ficha se refiere a la conservaciónrestauración, este campo de documentación se amplía significativamente. Unas veces, como mera información o muestra del estado de la obra, y otras, como datos concernientes al proceso de intervención.

\section{Los criterios de selección de campos}

La selección de campos se ha basado en criterios objetivos, sobre la obra, objeto o producción artística, la autoría y la localización. Cuestiones o criterios valorativos más subjetivos, se reservan a los campos del final.

El orden y jerarquización de parámetros dentro de los campos es el que ofrece más complejidad, pues cada obra tiene sus circunstancias particulares y puede suceder 
que, en ocasiones, prime la ubicación sobre la técnica, o la autoría sobre la propia obra (caso en que interese conservar y estudiar una pieza por el origen o el autor, no porque la pieza en sí tenga un valor estético o artístico notable). Este modelo se propone para facilitar el análisis y para poder catalogar las obras, de manera que también se tiene en cuenta la posibilidad de jerarquización o descripción de parámetros particulares no contemplados hasta el momento, ofreciendo una cierta flexibilidad, según las circunstancias de la obra.

Los criterios propuestos son los siguientes:

\section{Criterios objetivos: datos técnicos y formales. La autoría ${ }^{14}$}

Aquí se incluyen los datos generales, como realización, técnica, fecha, nombre autor, título, dimensiones, ubicación, temática; es decir, una descripción formal que incluiría la tipología y una descripción objetiva, sin lugar a interpretaciones. También aparecen los temas legales (propiedad, derechos, etc.).

\section{Criterios en base a la observación artística. Iconografía}

Apartado en el que se incluyen parámetros más subjetivos y de valoración, como la estética o estilo, intención del autor o de la obra, contexto artístico, social, etc. Pero por otro lado, también incluiremos parámetros o campos referidos a la valoración crítica del arte, y parámetros útiles para la difusión de la obra, medios de comunicación, redes sociales, etc.

\section{Criterios en base a la conservación, estado de la pieza o conjunto}

En este campo se incluye la evaluación del estado de conservación de la obra. Estos datos son susceptibles de irse ampliando con documentación gráfica sobre sus procesos de degradación. Se incluye documentación si existe, como algún plan de conservación, dossier, etc.

\section{Criterios en base a la restauración}

Si se ha llegado a esta fase, se ampliará la ficha técnica con los datos y campos necesarios según el criterio del equipo de restauración que deberá contemplar en primer lugar el examen y valoración de su estado de conservación.

\section{Criterios en base a la valoración externa}

Se puede ampliar el informe incluyendo toda la información publicada en los medios de comunicación, según la repercusión de la obra. Por otro lado, se propone incluir en este apartado si existe una valoración económica de la misma, así como las circunstancias que han acompañado este hecho.

\section{Criterios en base a la valoración personal}

Según el tipo de obra estudiada, se puede dar el caso de que la opinión del profesional que realiza la ficha esté enfrentada con la de otros profesionales. En este caso, se debe dejar claro que se exponen valoraciones y criterios personales y se debe justificar adecuadamente.

7. Criterios en base a la valoración extraída de la opinión o datos vertidos por el artista en las entrevistas y/o el entorno de la obra

La entrevista es una de las herramientas complementarias más interesantes que puede ayudar a la comprensión de algunos datos fundamentales para poder valorar la necesidad de conservación-restauración de una obra. La importancia de poseer información de primera mano (artista, organización) no es fácilmente sustituible. Si se poseen entrevistas, aunque no las haya realizado el mismo profesional, se aportarán como documento de especial importancia.

\section{Modelo de registro: conjunto de fichas propuesto}

En la siguiente tabla (Tablas 1-7), se desarrolla el modelo de registro propuesto. Se muestra en formato de tabla para organizar mejor los campos y parámetros seleccionados, aquí expuestos. En algunos espacios explicamos parte de lo que se pretende describir en cada apartado.

\section{Modelo de registro propuesto [Tablas 1, 2, 3, 4, 5, 6, 7]}

Especificaciones sobre campos o parámetros empleados en la Tabla:

*1 Se pondrá el nombre real del autor. Pero este dato no se hará público (en publicaciones o cesión de datos a terceros) en el caso de que el autor prefiera el anonimato -y esto será respetado-, o en caso de que pueda peligrar la integridad de la obra por algún motivo relacionado.

*2 Se hará público si es adecuado para la obra; si se pone en riesgo, no se hará público. Tampoco si hay riesgo de multa para la autoría o responsables.

*3 Puede darse el caso de que, aun estando ante una obra de arte urbano -por emplear técnicas, procesos y procedimientos, estético o incluso temática y mensajes propios del arte urbano-, por su iniciativa y realización privada, en espacio privado, pierda su carácter de obra independiente pública, que es parte de la esencia del Street art. 


\begin{tabular}{|c|c|}
\hline \multicolumn{2}{|c|}{ REGISTRO PARA ANÁLISIS, DOCUMENTACIÓN Y CATALOGACIÓN DE OBRAS DE ARTE URBANO } \\
\hline \multicolumn{2}{|c|}{$\begin{array}{l}\text { Datos de quien-es registran la obra: } \\
\text { - Nombre de quien-es emite los datos (redacta) la ficha } \\
\text { - Datos de entidad/grupo/motivo/finalidad de la ficha } \\
\text { - Fecha de redacción de la ficha } \\
\text { - Motivo } \\
\text { - Tipo de publicación, si la hay (especializada, no especializada, catalogación, estudio académico...) }\end{array}$} \\
\hline \multicolumn{2}{|c|}{ I- FICHA TÉCNICA estándar (resumen) de la obra } \\
\hline \multicolumn{2}{|c|}{$\begin{array}{l}\text { 1. Título de la obra } \\
\text { 2. Autoría } \\
\text { 3. Tipología de obra: técnica, soporte (estilo o estética) } \\
\text { 4. Localización } \\
\text { 5. Fecha de realización } \\
\text { 6. Situación legal de la pieza (origen y actualidad) } \\
\text { 7. Estado general de la pieza (protegida o no, conservada o no, restaurada o no...) } \\
\text { 8. Cambio en su situación jurídica } \\
\text { 9. Importancia de la pieza (formal, técnica, emocional, social, grupal o general...) } \\
\text { 10. Documentación previa y su procedencia (documentada antes/no documentada } \\
\text { previamente) }\end{array}$} \\
\hline \multicolumn{2}{|c|}{ II-FICHA TÉCNICA Y FORMAL } \\
\hline \multicolumn{2}{|c|}{ (campos de datos descriptivos formales técnicos e iconográficos) } \\
\hline 1. TÍTULO dE LA PIEZA & [Si lo tiene o si se le conoce con algún nombre] \\
\hline \multicolumn{2}{|l|}{ 2. FECHA DE REALIZACIÓN } \\
\hline 3. AUTORÍA *1 & $\begin{array}{l}\text { Datos biográficos básicos. [Fecha nacimiento } \\
\text { autor/es, tipo de obra que trabaja; } \\
\text { documentación básica: web o algún enlace } \\
\text { donde podamos ver otras obras o entrevista...] }\end{array}$ \\
\hline 3A. TIPO DE AUTORÍA & $\begin{array}{l}\text { 1) INDIVIDUAL/COLECTIVO } \\
\text { 2) NOMBRE ARTÍSTICO O FIRMA } \\
\text { 3) NOMBRE REAL (si se sabe) } \\
\text { 4) DESCONOCIDA }\end{array}$ \\
\hline $\begin{array}{l}\text { 3B. RESPONSABLE/S DEL } \\
\text { MANTENIMIENTO DE LA OBRA. } \\
\text { 1)SI } \\
\text { 2)NO } \\
\text { 3)QUIÉN/-ES }\end{array}$ & $\begin{array}{l}\text { [Los responsables de la pieza no tienen por qué } \\
\text { ser los autores. Estos pueden desinteresarse o } \\
\text { desvincularse por completo de las obras } \\
\text { responsables legales (o de la conservación, } \\
\text { etc.) implicados en la realización de la misma, } \\
\text { alguien que privadamente ha pedido que se } \\
\text { realice una obra en su propiedad, o muro, en }\end{array}$ \\
\hline & $\begin{array}{l}\text { casos de un festival, o de alguna convocatoria } \\
\text { pública de institución, un museo o galería, etc.] }\end{array}$ \\
\hline $\begin{array}{l}\text { 4. LOCALIZACIÓN, SOPORTE Y DESCRIPCIÓN } \\
\text { DE LA OBRA }\left({ }^{*} 2\right) \text { : }\end{array}$ & $\begin{array}{l}\text { [Según la singularidad de la pieza, puede ser } \\
\text { más importante la localización y radique ahí su } \\
\text { fuerza comunicativa o social, y otras veces, } \\
\text { puede ser en sí, como pieza artística, o por la } \\
\text { singularidad del soporte, de difícil acceso y } \\
\text { producción, por ejemplo.] }\end{array}$ \\
\hline $\begin{array}{l}\text { 4A. DESCRIPCIÓN GENERAL DE } \\
\text { CONJUNTO: SOPORTE- LUGAR } \\
\text { TECNICA }\end{array}$ & 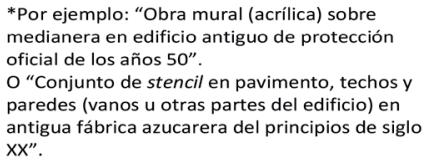 \\
\hline
\end{tabular}

\section{B) LOCALIZACIÓN}

\section{Ba. DIRECCIÓN:}

Calle o vía y número. Población y CP. País.
4Bb. GEOLOCALIZACIÓN O COORDENADAS DE POSICIÓN (si se tienen)

4BC. DESCRIPCIÓN DETALLADA DEL LUGARY LA LOCALIZACIÓN:

[Captura de imagen, coordenadas de mapa de la ubicación; imágenes tomadas con la ayuda de Drones, para obtener una perspectiva de contexto del lugar, o imagen más adecuada y completa de obras de dificil acceso), y tamb incrion un sobre el estado de la pieza, Asínien un cambios o posibles deterioros. obras cercanas, y el hábitat de la pieza).]

\section{1) Entorno Urbano o Rural}

2) Exterior o Interior

3) Tipo de vía o lugar

* Se debe ser lo más exacto posible en la descripción.

Si es calle, avenida, patio, ruinas, plaza, carretera, etc

-Si es junto a una zona industrial, o vías de tren, puentes, solares, pasos a nivel, garajes, etc.

\section{C. SOPORTE}

4Ca. TIPO DE SOPORTE: ESTÁTICO O MÓVIL

T) como farolas, marquesinas, kioscos, semáforos, señales de tráfico, pavimentos (suelos, aceras);

\begin{tabular}{|c|c|}
\hline & $\begin{array}{l}\text { caja de luz, contadores de luz/agua, etc; } \\
\text { señaléticas varias: pasos de peatones; } \\
\text { techumbres o zonas de resguardo (paradas bus, } \\
\text { tren, etc.), marquesinas....Muros o partes de } \\
\text { edificios/construcciones públicos (colegios, } \\
\text { puentes, estaciones de metro/bus...) } \\
\text { 2) Mobiliario urbano-público móvil: vagones } \\
\text { metro, coche policía...; contenedores de } \\
\text { basura, papeleras no estáticas; vehículos } \\
\text { abandonados... } \\
\text { 3) Mobiliario urbano privado: Muros o partes } \\
\text { de edificios/construcciones: medianera, } \\
\text { fachada... puertas/ventanas o marcos, } \\
\text { vidrieras... } \\
\text { 4) Elementos de reposición: bombillas, tierra en } \\
\text { maceteros, carteles/posters de publicidad } \\
\text { entidades públicas o privadas; elementos } \\
\text { decorativos (adornos navideños, festivos...) } \\
\text { 5) Elementos naturales: árboles, piedras del } \\
\text { entorno, plantas...y sus soportes. ETC. }\end{array}$ \\
\hline $\begin{array}{l}\text { 4Cb. MATERIAL O } \\
\text { MATERIALES DEL/LOS } \\
\text { SOPORTES }\end{array}$ & $\begin{array}{l}\text { Material-es: metal, ladrillo, mampostería, } \\
\text { hormigón, vidrio, madera... } \\
\text {-Si se puede especificar más, se hará. }\end{array}$ \\
\hline \multicolumn{2}{|c|}{ 4D. DESCRIPCIÓN DE LA OBRA, EN DETALLE } \\
\hline $\begin{array}{l}\text { 4Da. DESCRIPCIÓN } \\
\text { TÉCNICA/ARTÍSTICA }\end{array}$ & $\begin{array}{l}\text { 1) Técnica artística o creativa: pintura, } \\
\text { taladrado, poster, pegatina... } \\
\text { 2) Materiales (aerosol, óleo, acrílicos, témpera, } \\
\text { papel...) } \\
\text { 3) Dimensiones } \\
\text { 4) Proceso creativo } \\
\text { 5) Tipología de arte urbano donde se puede } \\
\text { adscribir: stencil, mural, poch, croché... } \\
\text { [Nombres técnicos anglos o en español, } \\
\text { francés...] }\end{array}$ \\
\hline $\begin{array}{l}\text { 4Db. DESCRIPCIÓN } \\
\text { ICONOGRÁFICA: } \\
\text { Forma/contenido }\end{array}$ & $\begin{array}{l}\text { 1) Descripción formal (formas, composición, } \\
\text { color...) } \\
\text { 2)Temática: lo que representa (historia, } \\
\text { narración, si la hay) } \\
\text { 3) Iconografía: descripción de los elementos } \\
\text { artísticos (contenido simbólico, etc.) } \\
\text { 4) Estilo y/o estética } \\
\text { 5) Dimensión creativa: si proviene de idea } \\
\text { original, copia o referencia de obra existente }\end{array}$ \\
\hline
\end{tabular}

\begin{tabular}{|c|c|}
\hline 4E. ICONOLOGÍA & $\begin{array}{l}\text { La obra dentro del Contexto de creación } \\
\text { artística y comunicación, histórico y social. }\end{array}$ \\
\hline & $\begin{array}{l}\text { 1) Valores creativos y técnicos artísticos } \\
\text { respecto a su contexto artístico concreto } \\
\text { (corrientes estéticas imperante/momento } \\
\text { concreto-fechas). } \\
\text { 2) Valores social (significado de la obra y/o su } \\
\text { autoría o lugar por su momento concreto) } \\
\text { 3) Valoración dentro del Arte urbano (en su } \\
\text { enlace con público, mensajes, contexto } \\
\text { histórico-social...): Por ejemplo, es diferente } \\
\text { valoración la que necesita una obra en el } \\
\text { contexto de la reivindicación en el } 15 \mathrm{M}, \text { si } \\
\text { habla de ello, o no... }\end{array}$ \\
\hline $\begin{array}{l}\text { 4F. CONTEXTO SOCIAL } \\
\text { Tipo de entorno social donde se } \\
\text { ubica la obra a registrar/analizar }\end{array}$ & $\begin{array}{l}\text { 1) Contexto social } \\
\text { 2) Contexto económico } \\
\text { 3) Contexto histórico y artístico (si hay } \\
\text { escultura pública, o es un barrio de un casco } \\
\text { histórico o antiguo...) } \\
\text { 4) Posibles intereses de la zona (especulativos, } \\
\text { derribo, remodelación, estable...) }\end{array}$ \\
\hline \multicolumn{2}{|c|}{ 5. VINCULACIÓN LEGAL Y ORIGEN (PROPIEDAD, ETC.) } \\
\hline $\begin{array}{l}\text { 5A. ORIGEN Legal }\left({ }^{*} 3\right) \\
\text { [De dónde parte la iniciativa de la } \\
\text { obra] }\end{array}$ & $\begin{array}{l}\text { 1) Oficial - encargo privado } \\
\text { 2) Oficial - encargo público: dentro de una } \\
\text { convocatoria pública, en un marco de legalidad } \\
\text { o institucional (festivales, concursos...) } \\
\text { 3) Independiente }\end{array}$ \\
\hline $\begin{array}{l}\text { 5B. SITUACIÓN ILEGAL/ALEGAL O } \\
\text { LEGAL DE LA OBRA } \\
\text { [Según su ubicación] }\end{array}$ & $\begin{array}{l}\text { [Puede coincidir con el origen de la obra } \\
\text { (campo 3B), o no: porque aunque un festival } \\
\text { haga una convocatoria, por ejemplo, y se } \\
\text { realice la obra en su marco, después, el soporte } \\
\text { y la obra quedan desligadas de toda } \\
\text { responsabilidad y puede entrar (o volver) a } \\
\text { situación ilegal, cuando nació "de forma legal" } \\
\text { u oficialmente.] }\end{array}$ \\
\hline $\begin{array}{l}\text { 5C. EXPOSICIÓN O } \\
\text { MUSEALIZACIÓN } \\
\text { [El estado de la pieza para ello] }\end{array}$ & $\begin{array}{l}\text { *Si ha estado en alguno de estos procesos, } \\
\text { detallar los agentes culturales intervinientes: } \\
\text { colectivos, asociaciones, fundaciones, fondos } \\
\text { museísticos, galerías... }\end{array}$ \\
\hline 5Ca. En caso de ser obra & $\begin{array}{l}\text { 1) Nombre de evento } \\
\text { 2) Detalles del evento (programa de actividad) }\end{array}$ \\
\hline
\end{tabular}

Tablas 3 y 4 .

Tablas 1 y 2. 


\begin{tabular}{|c|c|}
\hline $\begin{array}{l}\text { por encargo o en festival } \\
\text { (o para una exposición...) }\end{array}$ & $\begin{array}{l}\text { 3) Contrato (pago, disposiciones, derechos } \\
\text { sobre la obra y su reproducción) } \\
\text { 4) Financiación (entidad o patrocinio y cuantía } \\
\text { presupuestada para la producción) } \\
\text { 5) Situación de derechos de imagen: tipos de } \\
\text { licencia bajo la que se postula la obra } \\
\text { (copyright, copyleft...) } \\
\text { 6) Tasación (especulativa/real, si se da el caso) }\end{array}$ \\
\hline \multicolumn{2}{|c|}{ (campos con datos documentales) } \\
\hline \multicolumn{2}{|c|}{ 6. DOCUMENTACIÓN GRÁFICA (descriptiva-técnica, o de medios de masas, difusión, etc) } \\
\hline 6A. FOTOGRAFÍAS (importante) & $\begin{array}{l}\text { [Foto general y de detalle; con datos de la } \\
\text { imagen y autoría, permisos y licencias] }\end{array}$ \\
\hline $\begin{array}{l}\text { 6B. AUDIOVISUAL (cualquier } \\
\text { soporte y formato, analógico o } \\
\text { digital) }\end{array}$ & $\begin{array}{l}\text { Tipo de soporte/producción: } \\
\text {-Vídeo (producción particular) } \\
\text {-Recreación virtual } \\
\text {-QRCode... } \\
\text {-Cine, cortometraje, spot publicitario, } \\
\text { videoclip... (producción gran escala), etc. }\end{array}$ \\
\hline 7. DOCUMENTACIÓN BIBLIOGRÁFICA & $\begin{array}{l}\text {-Reseñada en libros, artículos de prensa } \\
\text { general o especializados; difusión o } \\
\text { divulgación. } \\
\text {-Online o en papel. }\end{array}$ \\
\hline $\begin{array}{l}\text { 8. DOCUMENTACIÓN APARECIDA EN } \\
\text { MEDIOS DE COMUNICACIÓN DE MASAS O } \\
\text { REDES SOCIALES (generales o particulares) }\end{array}$ & $\begin{array}{l}\text { Sobre la imagen o noticia de la obra, } \\
\text { referencias de difusión o divulgación en } \\
\text { reportaje, noticia, estudio, investigación } \\
\text { científica o en: } \\
\text { 1) Internet: Web, blog personales, redes como } \\
\text { Vimeo, Youtube, facebook, instagram, Tbr, } \\
\text { twitter, Flikr, etc. } \\
\text { 2) Tv (archivos en analógico o digital) } \\
\text { 3) Radio (archivos analógicos o podcast) }\end{array}$ \\
\hline \multicolumn{2}{|c|}{$\begin{array}{l}\text { 9. LISTADO DE TAGS O HASHTAG IDENTIFICADORES } \\
\text { (Para relacionar temas u obras entre sí...) }\end{array}$} \\
\hline \multicolumn{2}{|c|}{ III. FICHA DEL ESTADO DE CONSERVACIÓN } \\
\hline 10. ESTADO DE CONSERVACIÓN & $\begin{array}{l}\text { 1) Bueno } \\
\text { 2) En estado de deterioro (con necesidades de } \\
\text { conservación) } \\
\text { 3) Ya deteriorado (con necesidades de plan de } \\
\text { restauración) }\end{array}$ \\
\hline $\begin{array}{l}\text { 11. DESCRIPCIÓN DEL ESTADO DE } \\
\text { CONSERVACIÓN }\end{array}$ & $\begin{array}{l}\text { Cualquier expediente, informe, valoración } \\
\text { técnica existente o de interés... }\end{array}$ \\
\hline 12. PLAN DE CONSERVACIÓN O PROTOCOLO & Cualquier expediente, informe, valoración \\
\hline ACONSEJADO & técnica existente o de interés... \\
\hline $\begin{array}{l}\text { 13. DOCUMENTACIÓN ADJUNTA DE } \\
\text { CONSERVACIÓN }\end{array}$ & $\begin{array}{l}\text { Cualquier expediente, informe, valoración } \\
\text { técnica existente o de interés... }\end{array}$ \\
\hline $\begin{array}{l}\text { 14. DOCUMENTACIÓN GRÁFICA Y } \\
\text { AUDIOVISUAL } \\
\text { (tipos de documentación) }\end{array}$ & $\begin{array}{l}\text { 1) Imagen panorámica de rango dinámico } \\
\text { amplio. } \\
\text { 2) Imagen hiperespetral. } \\
\text { 3) Videografía estereoscópica (3D) o inmersiva } \\
\text { 4) Documentación geométrica } \\
\text { 5) Documentación gráfica de alta resolución } \\
\text { 6) Audiovisual } \\
\text { 7) Reconstrucción virtual }\end{array}$ \\
\hline $\begin{array}{l}\text { 15. DOCUMENTACIÓN EN CASO DE ESTAR } \\
\text { SIENDO CONSERVADA LA PIEZA YA }\end{array}$ & $\begin{array}{l}\text { Cualquier dossier, de descripción técnica o } \\
\text { memoria de actuaciones llevadas a cabo }\end{array}$ \\
\hline \multicolumn{2}{|c|}{ IV. FICHA SOBRE INTERÉS DEL AUTOR-ES EN LA CONSERVACIÓN DE SU OBRA } \\
\hline $\begin{array}{l}\text { 16. ¿SE CUENTA CON EL DESEO DEL AUTOR- } \\
\text { ES DE PRESERVAR SU OBRA? }\end{array}$ & $\mathrm{SI} / \mathrm{NO}$ \\
\hline 16A. En caso de que sí & $\begin{array}{l}\text { 1) Él mismo se encargará de la conservación o } \\
\text { repinte, reposición de piezas, etc. } \\
\text { 2) Se encarga él, pero con ayuda o } \\
\text { asesoramiento necesarios } \\
\text { 3) Lo deja en manos de profesionales bajo su } \\
\text { supervisión } \\
\text { 4) Lo deja en manos de profesionales } \\
\text { totalmente } \\
\text { 5) No le interesa saber nada del tema, aunque } \\
\text { no le importa que se conserve/restaure }\end{array}$ \\
\hline 16B. En caso de que no & $\begin{array}{l}\text {-Preguntar los motivos al autor-a/s } \\
\text {-Detallar los motivos lo máximo posible } \\
\text {-Si se cuenta con material de archivo de la } \\
\text { opinión, añadir como documentación }\end{array}$ \\
\hline \multicolumn{2}{|c|}{ V. FICHA DATOS BÁSICOS en caso de Proceso de RESTAURACIÓN } \\
\hline 17. EQUIPO PROFESIONAL ENCARGADO & $\begin{array}{l}\text { Detallar profesional o equipo de profesionales; } \\
\text { Breve CV de ellos; entidad encargada, etc. }\end{array}$ \\
\hline $\begin{array}{l}\text { 18. ESTADO DEL PROCESO DE } \\
\text { RESTAURACIÓN }\end{array}$ & $\begin{array}{l}\text { Breve descripción de la situación: exponer en } \\
\text { qué grado o fase de restauración se encuentra } \\
\text { la obra: } \\
\text { 1) Iniciado: evaluación o establecimiento de } \\
\text { protocolo de actuación } \\
\text { 2) En estado de restauración }\end{array}$ \\
\hline 19. PLAN DE RESTAURACIÓN O PROTOCOLO & Medidas técnicas a tomar \\
\hline
\end{tabular}

Tablas 5 y 6.

\begin{tabular}{|c|c|}
\hline ACONSEJADO & \\
\hline $\begin{array}{l}\text { 20. DOCUMENTACIÓN ADJUNTA, TÉCNICA, } \\
\text { DE RESTAURACIÓN }\end{array}$ & $\begin{array}{l}\text { Cualquier expediente, informe, valoración } \\
\text { técnica existente o de interés... }\end{array}$ \\
\hline $\begin{array}{l}\text { 21. PLANIFICACIÓN DEL PROCESO DE } \\
\text { RESTAURACIÓN (SI SE DA EL CASO) }\end{array}$ & $\begin{array}{l}\text { Especificación de materiales, técnicas, } \\
\text { procesos... }\end{array}$ \\
\hline $\begin{array}{l}\text { 22. FECHA DE FINALIZACIÓN DEL PROCESO } \\
\text { DE RESTAURACIÓN }\end{array}$ & Aplacamientos, prórrogas, etc., si se diera. \\
\hline \multicolumn{2}{|c|}{ VI. FICHA DE SITUACIÓN DE PROTECCIÓN DE LA OBRA DE ARTE URBANO (tras restauración) } \\
\hline $\begin{array}{l}\text { 23. SITUACIÓN DE LA OBRA AL FINAL DE LA } \\
\text { RESTAURACIÓN. }\end{array}$ & Medidas de conservación tras la restauración. \\
\hline \multicolumn{2}{|l|}{$\begin{array}{l}\text { 24. SITUACIÓN DE LA OBRA RESPECTO A } \\
\text { PATRIMONIO ARTÍSTICO (BICOMUN) }\end{array}$} \\
\hline \multicolumn{2}{|l|}{ 25. BIBLIOGRAFÍA SOBRE EL CASO } \\
\hline \multicolumn{2}{|c|}{ VII. FINANCIACIÓN para la conservación (si se da el caso) } \\
\hline $\begin{array}{l}\text { 26. ENTIDADES FINANCIADORAS y DETALLES } \\
\text { SOBRE FINANCIACIÓN }\end{array}$ & $\begin{array}{l}\text { 1) Cuantía o presupuestos } \\
\text { 2) Motivaciones (si se sabe) } \\
\text { 3) Plan de conservación } \\
\text { 4) Finalidades concretas (exhibición, fondos, } \\
\text { catálogo...) }\end{array}$ \\
\hline \multicolumn{2}{|c|}{$\begin{array}{l}\text { 27. OBSERVACIONES PERSONALES ESPECIALES } \\
\text { (Sobre lo que se salga de los epigrafes, o consideraciones sobre lo expresado o sobre } \\
\text { documentación, etc.; posibles valoraciones de informes, profesionales, etc.) }\end{array}$} \\
\hline
\end{tabular}

Tabla 7

\section{Conclusiones}

La propuesta de registro para la realización de una ficha técnica, formal y crítica, con un amplio número de campos donde exponer toda la información y documentación concreta, forma parte de un posicionamiento, abierto a la reflexión, sobre los criterios que deben ser aplicados en el Arte Urbano, desde el punto de vista de la conservación.

Para ello, se han tenido en cuenta distintos niveles de interés y se han registrado desde los datos más básicos hasta los que implican la comprensión global del tema, como el contexto, su relación con lo representado, la composición, el estado de conservación material y los procesos de conservaciónrestauración.

El arte urbano tiene la suficiente entidad como para que sus obras sean catalogables, debiéndose de estudiar previamente, de forma analítica, crítica e histórica, desde diversos campos del conocimiento.

Aunque este estudio es una propuesta inicial, quiere ser una aproximación abierta, que permita seguir trabajando en esta línea.

El modelo de registro propuesto parte de parámetros seleccionados según las necesidades que presentan las obras de arte urbano, y debe ser testado por una mayoría de profesionales relacionados con el arte urbano, expertos en diversas materias entre las que se incluye la de la conservación-restauración.

De forma trasversal a este estudio, se observa la necesidad de crear un glosario de términos de uso en el arte urbano, en varios idiomas. Así como un diccionario o glosario de técnicas específicas de arte urbano. 


\section{Notas}

[1] Arte Urbano, Street Art. Se refiere a la parte artística gráfica en general, ya que analizar sus diferencias no es el objetivo de este estudio (grafiti, postgrafiti y otras manifestaciones estéticas independientes) realizadas en espacio público; ilegales o no, incluidas las obras realizadas al amparo de festivales, con libertad de temática sin censuras previas ni motivaciones especulativas y comerciales, desarrolladas en el espacio público.

[2] MEPI: Manifestaciones estéticas públicas independientes. Según Luis Martín, en su texto La conservación de manifestaciones estéticas, públicas e independientes, el concepto significa: "intervenciones realizadas en el espacio urbano. Nacen por iniciativa propia, sin apoyo de la institución ni fines comerciales. (Op. referenciada en Bibliografía)

[3] Por equipo de profesionales nos referimos a todos los actores que intervienen en la petición de conservación de una pieza u obra arte urbano: artistas o autores, historiadores del arte, gestores culturales (de instituciones públicas o asociaciones), críticos, difusores y otros agentes que puedan intervenir.

[4] Término explicado por Javier Abarca en su tesis doctoral: ABARCA SANCHÍS, F. J. (2010). El postgraffiti, su escenario y sus raíces: graffiti, punk, skate y contrapublicidad. Tesis doctoral. Facultad de BBAA. Universidad Complutense de Madrid. Madrid. Pág. 25.

[5] Tomando el ejemplo del investigador Fernando Figueroa Saavedra, que escribe Grafiti (con mayúscula) cuando se refiere al movimiento cultural (no sólo a la técnica), tal como explica en su libro El grafiti de firma (pág. 6), aquí escribimos Arte Urbano (en mayúsculas) al referirnos al movimiento artístico y cultural que engloba los distintos estilos, estéticas, técnicas y lenguajes, así como vías culturales y sociales. (Op. referenciada en Bibliografía).

[6] Nos sentimos cercanos a lo que el historiador y crítico de arte, Rafael Schacter refiere en uno de sus artículos y aportaciones a la teoría del arte urbano, y es que el Arte Urbano es un período más dentro de la Historia del Arte, como lo es el Manierismo, o el Barroco, etc. (ver referencia a este artículo en la Bibliografía).

[7] Grupo de arte urbano y conservación, vinculado al GEIIC, desde 2015.

[8] Una definición válida de arte urbano, según la autora, podría ser: arte realizado en espacios públicos, tanto con dimensión expresiva y de comunicación directa con un público no seleccionado, como de dimensión estética con sus propios códigos, lenguajes, técnicas y procesos.

[9] Fernando Figueroa Saavedra, Felipe Gálvez, Gabriela Berti y Javier Abarca, investigando en el panorama del grafiti en el territorio español, y otros estudiosos del street art y el grafiti, a nivel internacional.

[10] http://bit.ly/1oddZ5j Ejemplo de ficha de una obra de arte de la Colección del Prado en su web oficial; y ejemplo de una ficha en la Tate Britain de Londres: http://bit.ly/2dJxLCh.
[11] http://ceres.mcu.es/pages/Main Enlace a los museos (sus fichas completas de colección) estatales españoles. http://bit. ly/2dmpm7Y Catálogo General del Museo Cerralbo (acceso online).

[12] https://riunet.upv.es/handle/10251/49221 Ester López Rodríguez: "Propuesta de conservación documental de murales urbanos en el barrio del Carmen de Valencia"Trabajo doctoral.

[13] http://bit.ly/2dhPvZy Archivo del IAPH.

[14] Autoría, o autor, autores, autora, ya que el término artista tiene unas connotaciones más excluyentes o más definitorias sobre la actitud, conocimientos o interés en el arte.

\section{Bibliografía}

ABARCA SANCHÍS, F. J. (2010). El postgraffiti, su escenario y sus raíces: graffiti, punk, skate y contrapublicidad. Tesis doctoral. Facultad de BBAA. Universidad Complutense de Madrid. Madrid. [ http://eprints.ucm.es/11419/]

ARGÁN, G.C. (2010). Lo artístico y lo estético. Ed. Casimiro libros. Madrid.

BANKSY (2005). Wall and Piece. Random House, London.

BAUER, H.(1980). Historia del arte. Introducción crítica a la historia del arte. Taurus, Madrid.

BOZAL, V. (1996). Historia de las ideas estéticas y de las teorías artísticas contemporáneas, 2 vols. Visor, Madrid.

CARLSSON, B. y LOUIE, H. (2013). Street art. Recetario de técnicas y materiales del arte urbano. Ed. Gustavo Gili, Barcelona.

CALABRESE, O. (1987). El lenguaje del arte, Paidós, Barcelona.

CRUZ FERNÁNDEZ, P y HERNÁNDEZ NAVARRO, M.A. (eds.). (2005). La práctica de la crítica: el artista y el escritor críticos de arte. Asociación Murciana de Críticos de Arte. Murcia.

DE DIEGO, E (2015). Artes visuales en occidente desde la segunda mitad del siglo XX. Madrid: Cátedra.

FIGUEROA SAAVEDRA, FERNANDO (2014). El grafiti de firma. Minobitia textos. Madrid.

GAYA NUÑO, J.A. (1975). Historia de la crítica de arte en España, Iberoamericana, Madrid.

GOMBRICH, E. (1992). Lo que nos cuentan las imágenes. Ed. Debate, Madrid.

GUASCH, AM. (2000). El arte último del siglo XX. Del posminimalismo a lo multicultural. Alianza Forma. Madrid.

HAUSER, Arnold. (1975). Teorías del Arte. Ed. Guadarrama, Madrid, 
HAUSER, A. (1975). Historia social de la literatura y el arte, 3 vols, Guadarrama, Madrid.

HUNTER, GARRY (2012). Street Art. From around the world. London. Ed. Arcturus.

MARÍAS, F. (1996). Teoría del arte, Historia 16, Madrid.

MARTÍNFERNÁNDEZ, L. (2014). La conservación de manifestaciones estéticas,públicas e independientes. Trabajo Fin de Máster Universitario en Conservación del Patrimonio Cultural, Facultad de BBAA. Universidad Complutense de Madrid.

PANOFSKY, ERWIN. (1992). Estudios sobre iconología. Alianza Universidad, Alianza Editorial.

PANOFSKY, ERWIN. (1977). Idea. Contribución a la historia de la teoría del arte. Ediciones Cátedra, Madrid.

PANOFSKY, ERWIN. (1991). El significado de las artes visuales. Alianza editorial. Madrid.

PLINIO (1987). Textos de Historia del Arte, Visor, Madrid.

RAMÍREZ, J.A. (1996). Cómo escribir sobre arte y arquitectura, Ed. Serbal, Barcelona.

RIEMSCHNEIDER, B. y GROSENICK, U. (Ed.). (2001). Arte de hoy. Ed. Taschen. Köln.

RIPA, C. (1987). Iconología, Tomo 1. Ed. Akal. Madrid.

RUSSI, P. (2016). Grafitis. Trazos de imaginación y espacios de encuentro. Editorial UOC. Barcelona.

SENO Ethel; MCCORMICK, Carlo; SCHILLER, Marc; SCHILLER Sara; PASTERNAK, Anne; SERRA, J y Banksy (2010). Trespass: historia del arte urbano no oficial. TASCHEN BENEDIKT. London.

VASARI, G. (1957). Vidas de artistas ilustres, 5 vols, Iberia, Barcelona,.

VENTURI, L. (2004). Historia de la crítica de arte. Colecc. Debolsillo. Ed. Random House Mondadori. Barcelona.

VAL CUBERO. A. (2010). Una aproximación metodológica en el análisis de las obras de arte. (Tesis doctoral) Departamento de Periodismo y Comunicación Audiovisual. Universidad Carlos III. Madrid.

VVAA (2014). Escenas del graffiti en Granada. (Ramón Pérez Sendra Ed.). Editan: Ciengramos y TRN Laboratorio artístico transfronterizo.

VVAA (2016).“Propuesta de evaluación cultural de Bienes Muebles de Patrimonio religioso". Revista digital GE-Conservación, Madrid. p. 45-57.

WINCKELMANN, J. (1987). Reflexiones sobre la imitación del arte griego en la pintura y en la escultura. Edit. Aguilar. Madrid.
WOLFFLIN, H. (1924). Conceptos fundamentales en la historia del arte, Calpe, Madrid.

\section{Vínculos web}

ABARCA, J. Urbanario. http://www.urbanario.es "El papel de los medios en el desarrollo del arte urbano".04-04-2011. Versión corregida del artículo del mismo título publicado en la revista de la AACA, no 12, septiembre de 2010. Madrid. [consulta: 21/09/16].

ASALTO PRODUCCIONES. Festival Asalto. http://www. festivalasalto.com [consulta 21/09/16].

BANKSY (2012). Exit through the gift shop. Película. Filmin. Plataforma de cine online. https://www.filmin.es/pelicula/exitthrough-the-gift-shop [consulta: 25/09/16].

BOA MISTURA: "La vida es un estado mental. Lodz, Polonia”. 2016. http://www.boamistura.com [consulta: 30/09/16].

CABRERA CHELIN, SEBASTIÁN y JIMÉNEZ MORALES, YOSELIN (2012): Arte Urbano como recurso publicitario en la ciudad de Santo Domingo, periodo 2010-2012. Escuela de Publicidad. Decanato de Artes y Comunicación. Universidad Apec Unapec. Santo Domingo, República Dominicana. Tesis-Arte-Urbano. http://es.scribd.com/doc/58915577/ [consulta: 21/09/16].

CAPEÁNS, Juan: “Qué es la Nueva Agenda Urbana?". 06/10/2016. http://ecosistemaurbano.org [consulta: 07/10/16].

DELAMADRID, G. Escrito en la pared. http://www.escritoenlapared. com/ Consulta general sobre artistas e imágenes de obras y sus referencias. [consulta: 21/09/16].

DE LA MADRID, G. Prieto, D. (2016.) Madrid Street Art Project: "Creación artística en la calle". http://madridstreetartproject.com. [consulta: 21/09/16].

ELTONO.COM: “Pintura generativa y participativa, Cité Brûlard (las "408") Besançon, Francia". 03/2016. http://www.eltono.com/es/ murals/les-408/ [consulta: 21/09/16].

FARAQUEL: “Obras interactivas de arte urbano en algunas calles en Italia" 10 /08/2013 http://bit.ly/2dvTnoK. [consulta: 20/09/16].

GAU (Galeria de Arte Urbana) Revista virtual: vol 04. -versión portugués- https://issuu.com/galeriadearteurbana/docs/gau_ vol4_pt [consulta: 21/09/16].

GENUS BONONIAE. (2016). "Extracto de conversación del restaurador de la exposición Street Art - Banksy \& Co. Arte allo stato urbano, Bologna". Audiovisual. Youtube, Marzo-2016. https://www.youtube.com/watch?v=09o-JDk5-yA [consulta: 25/09/16].

GRAFFITI.ORG. Art Crimes. The Writing on the Wall: "Glosario de términos sobre Graffiti". http://bit.ly/2esb5L5 [consulta: 25/09/16]. 
IPCE Instituto del Patrimonio Cultural de España: Patrimonio inmaterial/enlaces. http://ipce.mcu.es/conservacion/planesnacionales/ inmaterial.html [consulta: 21/09/16].

LA MIRADA DIFUSA: "Artistas urbanos. Filthy-luker". Agosto, 2016. http://www.lamiradadifusa.com/ [consulta: 21/09/16].

METRÓPOLIS: "Arte Urbano". Audiovisual, en RTVE web. http://bit. ly/2etONFV [consulta: 24/09/16].

MULAFEST.COM: (sobre Arte urbano en entorno social y cultural). http://mulafest.com [consulta: 20/09/16].

NIQUELARTE.ORG: “BIComún: Identidad, Memoria Colectiva y Bienes Comunes". 04/08/2014. http://bit.ly/2etAlH2 [consulta: 21/09/16].

NIQUELARTE.ORG: "Qué es BIComun". http://bit.ly/2ehOEsh [consulta: 25/09/16].

PLAZA, D. (realizador y guión). “Arte urbano”. Vídeos sobre Arte y sociedad. Recursos educativos. UNED. https://canal.uned.es/mmobj/ index/id/12408 [consulta: 21/09/16].
PRIETO, Diana: “Arte Urbano: Respuestas Abiertas a Preguntas Cerradas", 2016. http://bit.ly/2dvZERv [consulta: 21/09/16].

RECUERO, R. : "Entrevista a Laura Mema”. 06/09/, 2016. (modelos de entrevistas). http://www.plataformadeartecontemporaneo.com/pac/category/entrevista/ [consulta: 20/09/16].

SCHACTER, R.: "Street art is a period period or the emergence of intermural art". Hiperallergic.com. 31/06/16. http://bit. ly/2a62fjD [consulta: 25/09/16].

SLOWLY, Anita. Streetart Addicted: "Sr. Mu: O la imperiosa necesidad de contar-nos". ( modelos de entrevista). 25/06/2015. http://streetartaddicted.blogspot.com.es/ [consulta: 21/09/16].

UNESCO.ORG: "¿Qué es el patrimonio cultural inmaterial?". http://bit.ly/1 mQD3zp [consulta: 15/9/16].

WRITERSMADRID: "DARE, to be different" 26/05/16 http:// www.writersmadrid.es/blog-writers/page/2 [consulta: 21/09/16].

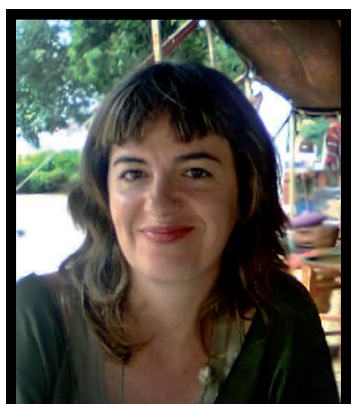

\section{María Isabel Úbeda García}

maribel.ubeda@gmail.com ; www.maribelubeda.org

@mariveh (twitter e instagram)

Licenciada en Historia del Arte y suficiencia investigadora en 2000, especialidad en Historia del Arte Moderno y Contemporáneo. Certificado de Aptitud Pedagógica en Ciencias Sociales. Técnico de Grado Superior en Fotografía artística. Miembro de la Asociación murciana de críticos de arte (AMUCA) y de AECA (Asociación Española de Críticos de Arte).

Ha trabajado en diferentes ámbitos de la enseñanza reglada y no reglada: Música e Historia del Arte, habilidades sociales, radio y teatro; en gestión cultural, con asesoramiento a artistas visuales, comisariado y edición de textos sobre arte, como: AMUCA, catálogos de exposición Salón de la Crítica, Murcia; ALBIAC -Bienal de arte. Almería-, y A la deriva. Asociación cultural: Libros A la deriva. Ha ejercido la crítica de arte para la Galería Acanto y AMUCA. También realiza fotografías, maquetación, diseños y dibujos para diversas webs, merchandasing (Universidad de Murcia), cartelería y difusión en diferentes soportes y medios, así como edición audiovisual y contenidos culturales en línea (streaming, blogs, redes sociales). Actualmente compagina su actividad freelance en gestión cultural con el estudio y experimentación del arte y nuevas tecnologías en "pymientoproject", hacklab Almería. Es community manager de varias cuentas de artistas y galerías, realiza una importante actividad de divulgación en el Blog cultural que gestiona.

Investigadora independiente, forma parte del grupo de Arte Urbano del Grupo Español del International Institute for Conservation of historic and artistic works (GE-IIC), desde febrero de 2015. 